\title{
Spontaneous bilateral medial head of gastrocnemius muscle rupture
}

\author{
Kirsten van Langevelde, ${ }^{1,2}$ Paolo Spinnato, ${ }^{3}$ Maria Carpenzano, ${ }^{3}$ Antonio Moio ${ }^{3}$
}

${ }^{1}$ Radiology, Leids Universitair Medisch Centrum, Leiden, The Netherlands

${ }^{2}$ Radiology, HAGA teaching hospital, Den Haag, The Netherlands

${ }^{3}$ Department of Diagnostic and Interventional Radiology (IRCCS), Istituto Ortopedico Rizzoli, Bologna, Italy

\section{Correspondence to}

Dr Kirsten van Langevelde, kirstenvanlangevelde@gmail. com

Accepted 8 March 2019

\section{DESCRIPTION}

A 46-year-old woman was referred to our ultrasonography unit because of pain in the calves that initiated 8 days ago. At that time, she was wearing high heels and walking in a cramped manner. After 4 hours of walking on high heels she noticed severe pain in the calves bilaterally. The patient had no previous medical history and did not use medication. The patient developed a bilateral ecchymosis that started distally and extended upwards towards the popliteal fossa over a period of 1 week. At the day of the ultrasound, she had symmetrical, extensive haematomas located medially in the calves (see figure 1).

The ultrasound showed a partial tear of the medial head of the gastrocnemius (MHG) muscle at the location of the distal myotendinous junction in the right leg, a condition known as tennis leg (figure 2). In addition, a haematoma was present between the muscle bellies of the soleus and MHG, extending proximally over a maximum diameter of $3.6 \mathrm{~cm}$ (dotted red line in figure 2). The findings in the left leg were identical. The punctum maximum of the pain as pointed out by the patient corresponded to the area of the muscle tear. There was no deep-vein thrombosis either in the popliteal vein or in the calf veins. The patient was treated conservatively and recovered fully.

We described a case of bilateral tennis leg, caused by walking on high heels: this injury mechanism (without an actual trauma) has not been described previously as a cause of bilateral spontaneous medial head of gastrocnemius muscle rupture. There are several cases of unilateral spontaneous tennis leg which occurred due to namaz praying. ${ }^{1}$ Bilateral,

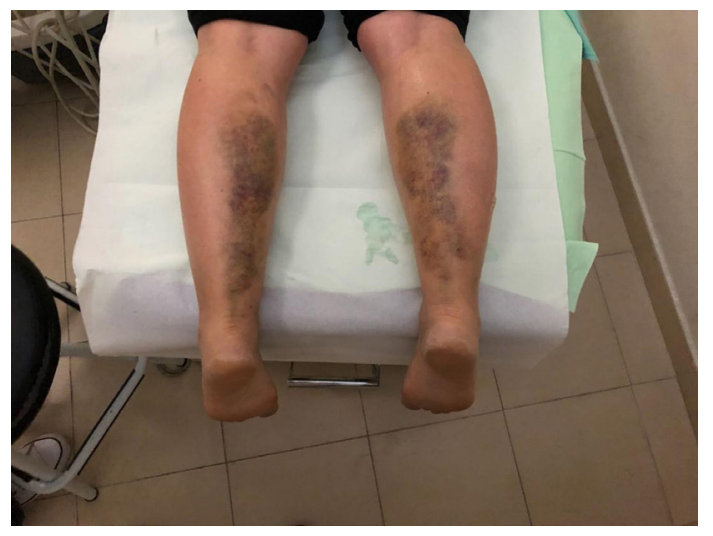

Figure 1 Photo of the calves in prone position showing symmetrical haematomas in the location of the medial head of the gastrocnemius muscle belly and extending towards the ankle.

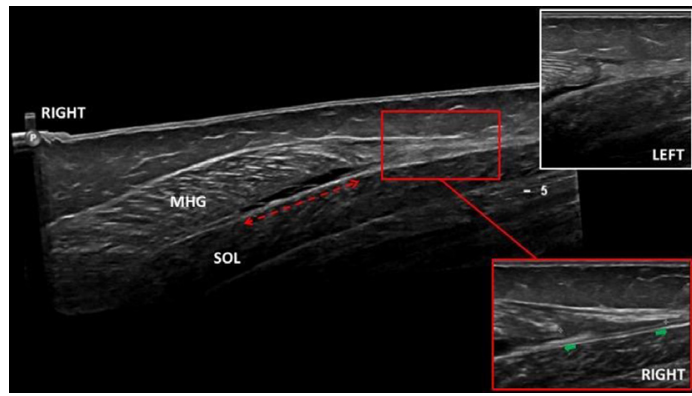

Figure 2 Panoramic view ultrasound image of the right leg in the sagittal plane: left side of the image is proximal, right side is distal. There is a hypo-echogenic haematoma (above the red dotted line) proximal to the myotendinous junction, in between the muscle bellies of the medial head of the gastrocnemius (MHG) and the soleus (SOL). The red box shows the tear at the right myotendinous junction in more detail, green arrows represent the extent of the tear. The echogenic muscle fibres are interrupted. Note that the haematoma is more hypo-echogenic than the muscle tear. For comparison, a detailed image of the tear at the left distal myotendinous junction is shown in the white box.

spontaneous rupture of the quadriceps tendon or Achilles tendon has been described in patients with renal disease, rheumatoid arthritis and osteogenesis imperfecta; and in case of medication use such as steroids, antibiotics (fluoroquinolone) and statins. ${ }^{23}$

The injury mechanism in tennis leg is that of a sudden push off when initiating a sprint, with forced dorsiflexion of the ankle while the knee remains in full extension.

The gastrocnemius muscle is prone to rupture because it traverses two joints and second because of the presence of a high density of fast twitch muscle fibres. The medial head is injured most often, however a haematoma between the medial gastrocnemius and soleus muscles without muscle rupture can occur. ${ }^{4}$

As for our patient, we hypothesised a cascade of injury, involving conditions such as pre-existent poor gastrocnemius-soleus flexibility, low-flexibility shoes (high heels) and muscle fatigue/ medialgastrocnemius stress secondary to walking in forced plantar flexion for 4 hours. These factors together may have caused microtearing followed by frank tearing of the medial head of gastrocnemius, which was then complicated by haematoma development. ${ }^{3}$

Ultrasound imaging is a low cost, easily available diagnostic tool that is considered the first step in assessment of muscle tears. ${ }^{5}$ The timing 
of the ultrasound examination is important, as between 24 and 48 hours after trauma, the haematoma between the muscle bellies is iso-echogenic which makes it likely that muscle tears are missed. ${ }^{6}$ After around 72 hours, the haematoma begins to liquefy and becomes hypo-echogenic making it easily visible with ultrasound as in our case.

We find the panoramic view a useful tool in assessing muscle tears, as the whole length of the abnormality can be imaged in one view.

\section{Learning points}

- Deep-vein thrombosis and tennis leg (medial head of gastrocnemius muscle tear) may cause similar symptoms of pain and calf tightness, and these entities often co-occur. The location of a haematoma in the calf is an important diagnostic clue towards muscle rupture.

- Ultrasound is the diagnostic modality of choice to assess a patient presenting with spontaneous pain in the calf.

- The first 48 hours after trauma, a muscle tear is easily missed on ultrasound as the haematoma is first iso-echogenic to muscle before it becomes hypo-echogenic.
Contributors KVL performed the ultrasound of the patient, annotated the images for publication and drafted the manuscript. PS drafted and reviewed the manuscript. MC performed the ultrasound and reviewed the manuscript. AM supervised the ultrasound and reviewed the manuscript.

Funding The authors have not declared a specific grant for this research from any funding agency in the public, commercial or not-for-profit sectors.

Competing interests None declared.

Patient consent for publication Obtained.

Provenance and peer review Not commissioned; externally peer reviewed.

\section{REFERENCES}

1 Yilmaz C, Orgenc Y, Ergenc R, et al. Rupture of the medial gastrocnemius muscle during namaz praying: an unusual cause of tennis leg. Comput Med Imaging Graph 2008;32:728-31.

$2 \mathrm{Kim}$ GK. The risk of fluoroquinolone-induced tendinopathy and tendon rupture: what does the clinician need to know? J Clin Aesthet Dermatol 2010;3:49-54.

3 Yu C, Giuffre B. Achilles tendinopathy after treatment with fluoroquinolone. Australas Radiol 2005:49:407-10.

4 Delgado GJ, Chung CB, Lektrakul N, et al. Tennis leg: clinical US study of 141 patients and anatomic investigation of four cadavers with MR imaging and US. Radiology 2002;224:112-9.

5 Bright JM, Fields KB, Draper R. Ultrasound Diagnosis of Calf Injuries. Sports Health 2017:9:352-5.

6 McNally E. Practical Musculoskeletal Ultrasound. 2nd edn. England: Churchill Livingstone, 2014.

Copyright 2019 BMJ Publishing Group. All rights reserved. For permission to reuse any of this content visit

https://www.bmj.com/company/products-services/rights-and-licensing/permissions/

BMJ Case Report Fellows may re-use this article for personal use and teaching without any further permission.

Become a Fellow of BMJ Case Reports today and you can:

- Submit as many cases as you like

- Enjoy fast sympathetic peer review and rapid publication of accepted articles

- Access all the published articles

- Re-use any of the published material for personal use and teaching without further permission

For information on Institutional Fellowships contact consortiasales@bmjgroup.com

Visit casereports.bmj.com for more articles like this and to become a Fellow 